\title{
PINA BAUSCH: PARA MAIORES DE 65 \\ ANOS
}

\author{
Solange Caldeira ${ }^{1}$
}

\section{Resumo}

Um lugar para fazer contatos - é este o título sugestivo de uma das obras mais atraentes de Pina Bausch, e também

a mais elástica: Kontakthof, criada e encenada por sua companhia em 1978. Em 2000, Bausch resolveu remontar a obra para pessoas com mais de 65 anos e para menores de 19 anos. Apesar dos 32 anos e da diversidade de elencos, Kontakthof continua simultaneamente atemporal e atual.

Palavras-chave: Pina Bausch, Dança teatro, dança na maturidade.

\section{Abstract}

A place to make contacts - this is the evocative title of one of the most attractive works of Pina Bausch, and also the most elastic: Kontakthof, created and staged by his company in 1978. In 2000, Bausch decided to restage the work with people over 65 years and younger than 19 years. Despite its 32 years of age and the diversity of its casts, Kontakthof continues simultaneously timeless and actual.

Keywords: Pina Bausch, dance theater, dance at maturity. 


\section{A Montagem}

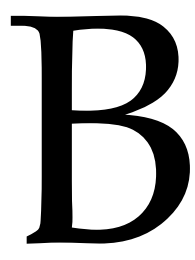
ailarinos de todo o mundo faziam peregrinação à cidade industrial de Wuppertal, na Alemanha, para uma audição na companhia de Pina Bausch. Portanto, não foi surpreendente que quando Bausch anunciou, em 1998, audição de um novo elenco para remontar Kontakthof, 120 homens e mulheres tenham aparecido. A diferença era que todos os candidatos tinham mais de 60 anos e ninguém jamais subira no palco como profissional antes.

Bausch foi específica, procurava idosos inexperientes, a maioria dos participantes do teste tinha pequena esperança de sucesso. Edith Rudorff, uma das 26 pessoas selecionadas, tinha ido, porque sempre estivera interessada no trabalho de Bausch. Por muito tempo tinha sido o seu desejo pôr o pé na sala de ensaio, para ver onde as peças tinham início, mas não sonhava fazer parte de Kontakthof. Werner Klammer, um homem que simplesmente gostava de se levantar e dançar, veio quando ocorreu a oportunidade, também "sem esperanças, medos e expectativas"(MACKRELL, 2002, p.15).

Jo AnneEndicott, bailarina da companhia de Bausch desde 1973, que dançou o Kontakthof original, em 1978, foi encarregada de ensaiar o elenco escolhido. "Eles todos tinham algum tipo de brilho em seus olhos. Eles viram isso como a chance de uma nova experiência de vida fabulosa, uma nova aventura" (MACKRELL, 2002, p.15).

A ideia de Bausch de montar com um elenco de idosos não era tão estranha quanto parece. Kontakthof é uma das suas obras de cunho mais confessional e íntimo, explorando loucamente a

1 Professora adjunta da Universidade Federal de Viçosa (UFV). Chefe do Departamento de Artes e Humanidades (DAH). Bailarina, atriz, coreógrafa e pesquisadora na área de dança e teatro. Doutora em Teatro (UNIRIO). Líder do Grupo de Pesquisa CNPQ Estudos Integrados em Dança, Teatro e Dança-Teatro.' irritação e os desejos que conduzem os relacionamentos adultos. A peça é muito mais sobre a personalidade dos artistas do que sobre suas técnicas de dança. E, conforme comenta Endicott: "Pina sempre teve um fantástico senso do que é 'in'. No momento, ser velho era 'in'. Esta peça é sobre ternura e agressividade, e essas pessoas tiveram essas emoções a vida inteira" (MACKRELL, 2002, p.15).

Pararealizarotrabalho, noentanto,esses homens e mulheres comuns, tiveram que aprender a se despirem metaforicamente e às vezes literalmente. Durante o trabalho, o elenco em pares, dança junto e compete em algumas partes de solo. Um homem e uma mulher exibem uma ternura ambígua entre si, tirando lentamente a maioria de suas roupas, outro casal apresenta uma cena de hostilidade, picando um ao outro na virilha, narinas e peito. Os artistas têm de revelar detalhes perturbadores de suas vidas passadas. Eles têm que correr e gritar como crianças hiperativas. Tudo isso é bastante difícil para os artistas jovens, com corpos perfeitamente afinados, mas para alguém comum, com complexo de ser impróprio, excesso de peso ou timidez, a exposição pode ser angustiante.

Endicott diz que muitos do elenco ficaram profundamente constrangidos ao tentarem fazer o que era solicitado: "Demorou muito para se obter o estado de espírito certo" (MACKRELL, 2002, p.16). Para Jutta Geike (54 anos, a mais nova intérprete), a coisa mais estranha foi o contato cada vez maior com os outros artistas, enquanto que para Klammer, 71 anos, o momento mais difícil foi a sequência em que ele tinha que entrar numa fila com os outros artistas e narrar uma história de amor de si mesmo. Para Rudorff, que assumiu o papel original de Endicott, o início de cada apresentação era sempre o pior. "Eu sou o primeiro a ir para frente do palco. A primeira vez que fiz isso pensei que ia ter um colapso no meio da cena" (MACKRELL, 2002, p.16).

Às vezes, os idosos sentiam que o materialqueestavam produzindoestava em contradição com o próprio temperamento, 
pois a maior parte do espetáculo é dançado e falado exatamente como ele foi criado, em torno do elenco original. Mas há passagens, como a seção de história de amor e as fofocas, dueto realizado por Rudorff e Geike, para o qual contribuíram com suas próprias memórias e sentimentos. "Esta é a cena mais emocionante. Nós pudemos dar forma à nossa imaginação" (MACKRELL, 2002, p.16), diz Geike.

O elenco sênior teve de ser induzido a abrir mão de suas inibições, e também tiveram seus sentimentos dissecados sem piedade. Em termos de dança pura, Kontakthof é uma das peças mais simples de Bausch e nenhum dos seus passos pede demais do elenco. Mas mesmo sem a exigência do virtuosismo, era necessário que os idosos adquirissem os níveis profissionais de precisão e coordenação. Endicott não encobre os problemas que teve na montagem: a marcação do ritmo, ficar em formação, aprender a não incomodar e lembrar os passos. "O processo de aprendizagem começa a ficar mais lento à medida que envelhecemos e precisamos de muita paciência. Não foram poucas as vezes que fiquei furiosa. Eu acho que todos nós ficamos um pouco frustrados"(MACKRELL, 2002, p.16).

Mas ninguém desistiu, e Endicott tem muito orgulho de dizer o quanto o elenco melhorou desde sua estreia em 2000. Mesmo assim, assistindo a performance em vídeo, é evidente que a emoção dos dançarinos toca as reservas instintivas, que momentos de vulnerabilidade são intensificados pelo envelhecimento de seus órgãos, que faíscas de lascívia e erotismo parecem imprudentes porque são inesperadas. Endicott acredita que o elenco atual se aproxima mais do espírito da produção original do que muitos dos jovens bailarinos que também dançaram a obra.

Apesar da intenção de dissolver oelenco sênior depois de uma curta temporada em Wuppertal, vários teatros em toda a Europa foram pedindo apresentação do espetáculo. Eles aceitaram e continuam aceitando alguns convites por ano.
Endicott diz que além de perder dois ou três do elenco original por doenças, os dançarinos parecem ter conseguido ficar mais jovens ao invés de mais velhos. Para todos os artistas, a peça tem sido uma inesperada vitória, uma reviravolta radical em suas expectativas de envelhecer. Como as palavras de Jutta: "Eu realmente gosto de estar no palco na frente da plateia. Eu não sabia disso antes" (MACKRELL, 2002, p.16).

\section{O espetáculo}

O que faz uma bailarina? No universo de Pina Bausch trabalha a experiência das relações humanas - o sofrimento e a alegria - o que dignifica um corpo em movimento. E os homens e mulheres de Kontakthof, têm muita experiência. O que eles trazem para Kontakthof é uma vida de aventura emocional. $\mathrm{O}$ que eles oferecem é um corpo de baile majestoso em toda a sua força e fraqueza. Ao som das músicas populares dos anos 1930 (a mais memorável é a música de cítara de Anton Karas), cadeiras alinhadas em três paredes formam o deslumbrante cenário utilitário de Rolf Borzik. Homens contra as mulheres, atração e agressão, criam tentativas engraçadas de conexão. Eles perseguem uns aos outros com sarcasmo, flertam e brigam descaradamente.

Relacionamentos adultos são revelados através dos cruéis jogos da infância. Às vezes é difícil dizer se o que se vê é uma festa social, uma louca festa do pijama ou brincadeiras no pátio da escola. A plateia ri das bobagens e ainda é convidada a dar-lhes moedas para montarem em um cavalo mecânico de balanço. No estoque a emoção sem restrições: a raiva, a dor, a vulnerabilidade, humilhação e desejo, todos juntos uma e outra vez.

Um grupo de pessoas coloca suas cadeiras na frente do palco, onde se sentam conversando com a plateia. Um homem passa ao longo da linha com um microfone. Eles estão todos descrevendo encontros românticos: o horror de um momento em 
que não se percebeu estar com espinafre nos dentes, a excitação de um novo parceiro, um nome constrangedor. Muitas das histórias são engraçadas. A maioria é cortada no meio, a experiência individual se torna um participante das necessidades humanas.

Um por um, os bailarinos vêm para frente, onde se colocam, mostram os dentes ou mantêm as mãos para fora, como se para uma inspeção. Uma das mulheres se queixa sobre os dentes ruins, o exame pode ser necessário. Em pares, eles apresentam um ao outro, gesticulando como assistentes do mágico, em seguida, batem um no outro. Cada pequena crueldade é aplaudida pelo resto do elenco, à espera em suas cadeiras. Uma sequência lembra o comportamento infantil: um homem persegue uma mulher gritando com um rato de brinquedo, reclamando sobre outros membros do elenco. Ao usar artistas mais velhos, parece que os comportamentos indignos se destacam mais. Mesmo quando eles fazem birras, a idade faz com que pareçam mais vulneráveis. Porém Kontakthof é extraordinariamente engraçado. Uma bailarina pede moedas ao público, porque ela quer montar um cavalo mecânico. Comentários são bruscamente interrompidos. Existem cenas de dança muito fortes em conjunto e outras em que param e discutem sobre a execução.

São três horas de espetáculo. E conforme é comum nas peças de Bausch, a repetição dos movimentos evidencia seus personagens presos a padrões. Porém os personagens de Kontakthof são mais livres - tem um bom tempo entre as explosões de crueldade e dor - mas o ritmo é pesado. Ainda assim é um trabalho realizado com absoluto empenho e digno de aplausos, principalmente a versão do elenco sênior, absolutamente bela, precisa, técnica e profissional.

As três horas de espetáculo voam como uma trilha sonora de memórias. Os personagens parecem estarnum teste para (talvez) uma performance enlouquecida de Alice no País das Maravilhas. Eles contam trechos de histórias em alemão ou inglês, sobem cuidadosamente sobre as cadeiras e riem de uma forma que é algo entre hilaridade e histeria. Os pares demonstram diferentes relações através da realização da mesma série de carícias, em grau crescente de violência, de modo que o que está acontecendo com o primeiro casal, no quarto já se transformou em uma guerra mutuamente sádica, com o macho batendo na fêmea. Como Bausch disse em uma entrevista "para algumas pessoas a vida seria chata sem violência em suas relações" (DOUGILL, 2009, p.23).

Depois, há os tons de bordel, de mercado de carnes, que vêm espontaneamente à mente vendo as mulheres exagerando o batom vermelho como prostitutas. Como de costume, esta é uma dança-teatro em vez de uma dança contemporânea, e como de costume, é um hino à mulher, sua aparência, seus ritos de acasalamento, seus jogos sexuais. As sequências de movimento são meticulosamente formadas a partir da linguagem corporal observada: tiques de desconforto e de adaptação, que as mulheres automaticamente adotam ao ajeitar uma alça de sutiã, arrumar subrepticiamente suas calças quando se levantam ou tentando alisar um vestido amassado.

As diferenças de força física, que são marcantes e interessantes nos artistas mais velhos - a poderosa dama antiga, o velho enrugado -, tornamse diferenças pequenas no elenco em que a qualidade crucial é o aplomb. No palco as personalidades são evidentes e Kontakthof detém a promessa de que a vida é um verdadeiro absurdo. Livre de constrangimentos narrativos, Kontakthof revela a essência explorada por Bausch ao longo de sua vida: a identidade humana e a busca interminável pela felicidade.

Como uma peça de dança-teatro, Kontakthof mal tem registros de dança. Mas quando o elenco se move em uníssono, a formação, o acréscimo de simples frases repetidas funciona brilhantemente como declarações potentes. E é isso que é tão extraordinário. 


\section{Kontakthof sem idade}

Essa ideia de remontar Kontakthof para três elencos diferentes sintetiza o gênio de Pina Bausch como grande inovadora, uma simples faísca que se desdobrou em uma chama duradoura.

Não foi a ideia mais fácil de traduzir, o projeto deveria durar três meses, mas levou um ano para ficar pronto. Os cidadãos seniores ficaram chocados ao descobrir que a companhia de profissionais do Tanztheater Wuppertal dançaria Kontakthof uma semana antes da estreia deles.

Pensavam que seu amadorismo ficaria exposto e que pareceriam tolos quando comparados com os profissionais. Porém, o que aconteceu foi completamente diferente, e muitos membros da companhia oficial de Bausch souberam, a partir da apresentação dos seniores, que os papéis já não eram deles.

Bausch raramente deu quaisquer explicações sobre o seu trabalho, mas ela escreveu brevíssimo preâmbulo de um livro sobre a sua obra, que começa com as palavras: "Kontakthof é um lugar onde as pessoas se encontram, pessoas que estão à procura de contacto" (SERVOS , 2003, p.8).

A cenografia simples de Rolf Borzik, cenógrafo de Bausch até sua morte prematura em 1980, evoca uma espécie de clube, na sua recriação de um salão de baile, um palco com cortinas, um piano e 30 resistentes cadeiras de madeira dispostas ao redor das paredes.

A eficácia visual deste ponto de encontro é maravilhosamente aumentada pela mais suntuosa das compilações musicais, construída em torno de um núcleo de tangos do período depois da República de Weimar e da época brutal do Terceiro Reich: especialmente corajoso, pois muitos dos cantores e líderes de banda incluídos nestas canções eram judeus.

São diversas as canções de Juan Llossas, German Tango King, incluindo Oh Fräulein Grete e Blonde Claire, schenk mir heht die eure, dois tangos maravilhosamente sedutores, cantados peloincomparável Leo Monosson, que fugiu dos campos de concentração para morrer sem um tostão nos E.U.A., fama há muito esquecida; o foxtrot swing, Abends in Der Kleinen Bar, cantado por RudiSchuricke; mais o quase esquecido Gnädige Frau, de Otto Stransky, e o fascinante instrumental Einmal ist Kleinmal, composto por Ralph Benatsky para um filme de 1937, tocado pela orquestra de Georges Boulanger.

Há várias músicas gloriosas, mas vale a pena mencionar estes extraordinários exemplos de uma era de ouro da dance music europeia orquestral - sempre obscurecida pela grande guerra que se seguiu - como o icônico Harry Lime Theme, de Anton Karas, do melhor filme noir de todos os tempos, de Carol Reed, O Terceiro Homem (1949). Juntamente com a elegância musical, há o charme adicional do film night em Kontakthof e um extrato de um lindo filme feito para o Bremen Radio Broadcasting Station por Theo Kubiak, intitulado Lebensraum em Gefahr (Endangered Environments), que mostra em closes preto e branco, um lago com patos e marrecos e patos, descritas na matéria com voz alemã traduzida (com entonações hilariante) por um fã devoto de Bausch, Richard Wilson.

É impressionante o brilho, simples e eficaz de coreografia de Bausch. Não há a menor referência à codificação da dança clássica, mas sim uma concentração no roteiro, muitas repetidas sequências de movimentos pequenos, simples e gestos, que se estendem para fora dos corpos, em movimentos sincronizados de tal complexidade, que é possível entender porque foram necessários quinze meses para que os seniores o apresentassem direito. Os corpos da dança, através dos vínculos de cada movimento isolado, apresentam a beleza individual de pérolas enfiadas em um longo colar.

Através de cenas episódicas, os 27 personagens ganham vida vibrante. Esta riqueza de personalidade é muito mais evidente no elenco sênior, que traz para o desempenho sua experiência de vida como Bausch tinha pretendido. $O$ papel feminino principal, de Edith Rudorff, foi retomado, 
alguns anos atrás, por Krista Lange, cujo desempenho também é excelente, mas muitos outros permanecem, como Werner Klammer e o muito distinto Pedro Kemp.

$\mathrm{O}$ agudo olhar de Bausch usou as formas e diferenças de idade, para acentuar preocupações universais. Os mesmos figurinos impecáveis que parecem dar ao elenco sênior um ar desamparado, aos jovens dão ideia de sensualidade. Vê-se as belas formas dos corpos jovens e as formas que faltam nos mais velhos. Os jovens riem dos próprios riscos e erros, nos mais velhos vê-se o temor. Mas o elenco sênior, embora não tão bom executante, é capaz de impregnar de significado seus gestos.

Kontakthof é um exemplo do que hoje se considera como a assinatura de Bausch. A dança não é muito mais do que alguns passos, com gestos naturalistas, sequências dramáticas e ameaçadoras. As repetições e sincronizações reforçam esta dramaturgia corporal, assim como a música antiga, mas ainda familiar, e as expressões de quase transe do elenco.

Apesar de ter um pouco de humor, Kontakthof retrata gente comum e seus relacionamentos. No entanto, as opções não são entre um relacionamento bom e um mau, mas entre um ruim e nada. Bausch parece nos lembrar que os seres humanos entre um mau relacionamento ou nenhum, escolhem o primeiro.

Vívido e desconcertante, Kontakthof é uma das produções mais minimalista de Pina Bausch. O cenário mostra um salão de dança e a coreografia é limitada a alguns passos de dança e de pequenos gestos. Mas, como sempre, a nuance vem daqueles que executam o trabalho-seus corpos, rostos, personalidades e manias. E neste elenco especial, de maiores de 65 anos, há uma profusão incrível de interesse humano no palco.

Em contraste com a suave beleza da juventude, estes homens e mulheres maduros imprimem à peça um novo $e$ extravagante sabor. Durante os minutos de abertura do espetáculo, quando cada bailarino passa e se olha em frente a um espelho invisível, todos nós também somos levados a olhar - fascinados pelo nariz adunco de um homem, pela barba muito bem feita de outro, pelos tornozelos finos que nos apresenta orgulhosamente uma mulher ou pelo olhar irônico de outra. E o mais importante, esses artistas mais velhos trazem nova e muitas vezes desconcertante química às partituras corporais criadas por Bausch. Kontakthof, que pode ser traduzido como "pátio de contatos", é um termo mais aplicável a bordéis - e, de certa forma, o espetáculo é estruturado como um jogo amoroso de três horas. Acompanhados por canções de amor, esses homens e mulheres flertam avidamente, como adolescentes. Para encontrar um parceiro usam a bajulação, humilhação, exibicionismo. E não é só sexo que eles querem, mas um simples momento de comunhão.

$\mathrm{O}$ fato de não esperarmos ver pessoas mais velhas envolvidas em busca de tal intimidade, faz as cenas parecerem duplamente chocantes. Quando uma mulher arruma seus cabelos brancos com um glamour especial e passa pelos homens mostrando a carne exposta em seus ombros, a carência de seu desejo é ao mesmo tempo cômica e assustadora. Do mesmo modo, quando as mulheres, em uníssono, ajustam as tiras do sutiã, sugam seus estômagos, puxam os vestidos com vaidade e incerteza, parecem mais vulneráveis.

Mas a idade também traz o poder. Uma cena é coreografada inteiramente a partir de pequenos atos de maldade, como um puxão de orelha, uma tapa no rosto, e é terrível ver estas punições entre velhos casais. Outro momento tem os dois sexos, alternadamente, dando ordens um para o outro - mais uma vez, com a experiência de uma vida.

O elenco sênior, não é apenas movido pela disciplina e coragem, mas também pelas histórias de vida que trazem com eles. O gênio de Bausch sempre revelou a individualidade de seus artistas, mas nessa encenação, ela criou uma dimensão fantástica ainda não visitada, cruel e terna.

Kontakthof é um triunfo da idade sobre a experiência. 
Sem surpresa, os bailarinos adolescentes habitam um universo físico diferente, com seus cabelos brilhantes, pele suave e aveludada, articulações flexíveis. E surpreendentemente, $\mathrm{o}$ efeito na coreografia Bausch é galvânica - as formas dos movimentos e os ritmos acelerados parecem mais nítidos sobre estes corpos mais jovens. Mas o sentido do tempo e do lugar é menos concentrado do que no desempenho dos idosos. Seriam esses adolescentes, vestidos em traje de noite formal e dançando músicas de 1930, netos do elenco sênior, ou aqueles os fantasmas de si mesmos jovens?

Essas diferenças são intrigantes e comoventes, mas o desempenho dos adolescentes fica muito aquém daquele dos idosos, muito mais rico na comédia surreal e de interesse humano. Kontakthof é sobre relacionamento de pessoas, sobre o complicado jogo da sedução, da comunicação, o elenco mais velho é capaz de trazer maior sutileza e veracidade às situações encenadas, maior conhecimento das propostas, maior vivência.

A disciplina complexa do trabalho envolve um pesadelo de logística - centenas de mudanças de roupa, ainda mais entradas e saídas, as questões de quem segue, quem se senta na cadeira e assim por diante - e esta evoluída estrutura permanece a mesma.

Mas, com poucas exceções, os artistas mais jovens não conseguem captar a mesma riqueza de caracterização que os idosos atingiram. O diálogo - tão crucial para o humor e personalidade de cada um - é muitas vezes indistinto e os adolescentes são mais inibidos que os mais velhos.

Como coreógrafa, Bausch não tinha nada a ver com o politicamente correto, mas neste ato inventivo, com este brilhante elenco, ela expôs a pobreza de nosso preconceito cultural em relação à idade - especialmente quando aplicado à dança. O elenco sênior que realizou Kontakthof mostrou o quanto podemos ser vitais e operantes independente da faixa etária, assim como o quanto a maturidade pode enriquecer teatralmente $o$ movimento corporal.
Realizada pelos idosos, Kontakthof é uma encantadora afirmação de experiência de vida. As emoções que Bausch destina ao trabalho - desejo, desilusão, desespero, ternura, vulnerabilidade, superação - são mais enfáticas quando enredadas na rica experiência de interpretação dos idosos. Mas, acima de tudo, esta é outra chance na vida para os atores-bailarinos. Depois dos 65 anos, ter a oportunidade de experimentar a excitante carreira de artista é algo notável: ainda mais, dado que esta nova vida para alguns já duram alguns anos.

Diz-se que a vida começa aos 40, em Wuppertal, começa aos 65 anos.

\section{Referências bibliográficas}

DOUGILL, David. Bausch's Kontakthof . In: The Arts. London: March 2009, p. 23-24. MACKRELL, Judith. Growing old disgracefully. In: The Guardian. London: November 2002, p 15-17.

SERVOS, Norbert. About Bausch. Pina Bausch explores the existential through movement. In: Dance International, Vol. XXXI, n. 2, Summer 2003. p. 8-12.

TANZTHEATER WUPPERTAL PINA BAUSCH (org.) Rolf Borzik und das Tanztheater. Text in english and french translated by Anne Surbant and Michel Adler. Wuppertal 2000.

WEISS, Ulli. Applausfotos. Pina Bausch Tanztheater Wuppertal. Mit einem Text in english by Raimund Hoghe. Hrsg. von den Wuppertaler Bühnen, Generalintendant Jürgen Fabritius und die "Freunde der Wuppertaler Bühnen". Wuppertal 1984.

WEISS, Ulli \& CHAMIER, Ille. Setz dich hin und lächle - Tanztheater von Pina Bausch. Text english and french by Anne Surbant \& Michel Adler. Prometh Verlag, Köln 1979. 